\title{
A Critical Perspective of the Gestalt Therapeutic Approach
}

\author{
Petros Orfanos \\ Education Advisor \\ Collaborative Scientific Staff, University of Athens, Athens, Greece \\ Email: petorfanos@yahoo.gr
}

\begin{abstract}
The present study constitutes an effort to present a complete critical perspective of the Gestalt approach. It is based on scientific articles concerning the therapeutic Gestalt approach and is accompanied by general information about the period which it developed and the concepts with which it connects. The use of the material targets the covering, to an extent but not in depth, the relevant issues concerning the Gestalt therapeutic approach which by itself constitutes one of the disadvantages of this critical perspective. The study presents an overview of the Gestalt approach through the presentation of its evolution, its ideas, its therapeutic goals and its techniques. Ultimately, it contributes to the dissemination of the tools used in this approach to consulting professionals and professionals who use or develop clinically therapeutic skills.
\end{abstract}

Keywords: Gestalt agents; Gestalt approach; holism; perceptual principles; problem solving

\section{Introduction}

The Gestalt approach is connected to the insightfulness of its founder, Fritz Perls (1893-1970), to the spirit of the times in which he lived, and to the professional growth of Perls himself as well as that of his wife, Laura Perls (1905-1990). For a better understanding, it is worthwhile to take into consideration certain facts of the period when the approach was shaped.

During the 1930s, Europe was characterized by radical change with new forms of expression and rapid growth in sciences and technology. Modern psychology was born as an independent field of study when Wilchelm Wundt (1832-1920), studied in his laboratory the psychological principles through a structural approach (that is, analyzing concepts as subtotals which identify one another with rules under logical-mathematical formulation). Perls became interested in philosophical quests in relation to existence, mindfulness and the experience of the world (The Gestalt Centre, 2021). He was in direct contact with the radical personality of Wilchelm Reich (1897-1957), with the philosophers of existentialism, with psychoanalysts and with the cofounders of the Gestalt approach (Yontef, 1993). The ideas of psychoanalysis, and more specifically the Reich approach, have influenced Perls greatly and have contributed to the foundation of the Gestalt approach (Witchel, 1973). Another one of Perls's mentors was the neurologist Goldstein who applied the principles of Gestalt to an organism. Perls's wife was a psychologist who had integrated her knowledge of music and dance into therapy. They met while they were both working in the Frankfurt Mental Health Center. In 1952, Perls and his wife established the Gestalt Institute in

New York which was run by Perls's wife until long after his death. Since the 1980s up to the present, the Gestalt therapy is widely known and continues to spread globally. 
The Gestalt approach is based on Perls and his associates' idea to create a new connective total which consists of various philosophical, methodological and therapeutic methods. This approach is a combination of psychoanalysis, Reich's psychosomatic therapies, psychodrama, existential approaches and Eastern philosophies. What is common among the techniques which are created or borrowed by the approach is that they support the individuals themselves to make the next step during their personal growth (Australian Institute of Professional Counselors, 2021). According to Perls, this different therapy is one of the defiant, existential forces in psychology (Witchel, 1973).

The positive element of this critical perspective is that it highlights the flexibility of and the potential for the creativity of the approach, describing simultaneously the concept of 'mindfulness' within its framework. What is characteristic in these interventions is the fact that mindfulness is not achieved exclusively through the dialogue or through behavior but through a combination of both within a framework in which the counselor and the individual interact authentically and both evolve.

\section{Main Representatives}

The principles of the Gestalt therapy were created and evolved by Fritz and Laura Perls and their partner, Paul Goodman (Yontef \& Jacobs, 2005). The main representatives of the Gestalt theory, with which the Gestalt therapy is connected, are Wertheimer, Koffka and Kohler. They believed that the comprehension of psychology could not be achieved with the analysis of the conscience into smaller parts but with the examination of the psychological phenomena as totals in organized forms which define the parts.

Max Wertheimer (1880-1943) worked with Wolfgang Kohler (1886-1941) and Kurt Koffka (18861967), all of whom constitute the core of the theoretical gestalt approach. Wertheimer was the student of the Austrian philosopher Christian Von Ehrenfels (1859-1932) who had introduced the Gestalt concept to philosophy and psychology. Wertheimer's publication concerning the phenomenon Phi, which refers to the illusion of the perception of movement under certain circumstances, signaled the inception of the Gestalt psychology in 1912. Koffka himself was also studying the phenomena of movement and rhythm and published the book, Principles of Gestalt Psychology. Kohler suggested the concept of insightfulness as a sudden comprehension of the structure of problems which leads to their solving without necessarily following a progressive and learned process.

Although Wertheimer, Kohler and Koffka were the leading figures of the approach, there should also be a reference to the contribution of Kurt Lewin (1890-1947), who continued with the idea that the Gestalt totals are created by the interaction between the potentials of the environment and the needs of the organism. His work magnified the work of the three main representatives of the approach on the one hand, by applying the principles to areas out of the perceptual psychology, and on the other, by explaining the theoretical repercussions of the Gestalt psychology (Yontef \& Jacobs, 2005).

\section{Basic Concepts and Ideas of the Approach \\ 3.1 Importance of the Word 'Gestalt'}

The Encylopedia Britannica refers to the Gestalt school in terms of the relationship of the approach with a modern study which relates to the perceptual organization. The basic principle is that the whole is more than the total of its parts, which means that, if we analyze the characteristics of its parts separately, we will not be able to comprehend the characteristics of the whole (Britannica, 2020). This means that, in order to comprehend a situation, analysis does not suffice. A compositional aspect needs to be adopted and each part perceived according to its position and 
function in relation to the wholeness. The verb gestalten in the German language means 'shape' (in German, it means 'formulate' as a psychological term); thus the word has a rich meaning, describing the way in which the parts have been arranged together. However, there is no equivalent term in English and the words 'shape' and 'form' are commonly used in the translation (Britannica, 2020).

Witchel (1973) contended that, according to Perls, the creation of wholeness (gestalt) is as old as the world since every organism creates such totals or wholes, to preserve itself. He describes the concept of Gestalt totals as units of experience. Generally, the Gestalt approach offers a way to include the qualitative characteristics of the form, the importance, and the value which other traditional approaches during that period had not taken into account. Its roots can be found in the academic Gestalt theory to which there have been additions by Perls (Witchel, 1973). The Gestalt approach constitutes a response to the empiricists by presenting a series of (innate) abilities or tendencies on which the perceptual organization is based.

\subsection{Roots of the Approach in the Academic Theory of the Gestalt Psychology and the Basic Perceptual Principles}

The Gestalt academic theory is based on a sequence of associations of the parts of the stimuli, mainly optical and acoustic, which according to the perceptual laws, constitute a form as follows:

- The distinction of form-setting, according to which every form can be perceived along with its setting;

- The proximity, according to which the closer spots can be perceived as continual;

- The confinement, according to which there is a tendency to fill in the gaps while perceiving the forms; and

- The symmetry, according to which there is an easier perception of symmetrical shapes as separate forms (Samartzi, 1995).

These innate laws are combined each time a stimulus is identified according to the morphological theory (Samartzi, 1995).

\subsection{Nature of the Process of Problem Solving}

The Gestalt theorists were interested in the nature of problem solving. Perls and Andreas (1969) argued that everyone should first have a dialogue between the two opposing parts, then appreciate the difference between these two opposing parts, as an oneness and integration of these two opposing forces. The perceptual principles which were presented before operate as factors of grouping. Based on these, the process of productive thinking includes the reorganization of the elements of a situation, the operation of the total based on the characteristics of wholeness and the production of logical assumptions and expectations. Generally, problem solving involves situations in which the repercussions of the available options should be taken into consideration. When the options are equally important, a (cognitive) 'conflict' is created within the individual. According to Festinger (1957), a student of the neo-Gestalt Kurt Lewin, the conflicting elements of a situation cause emotions of cognitive discomfort to the individuals i.e. conflict. The tension caused by the problematic situation is the one which initiates the processes for its solving because the individuals want to reduce the discomfort they feel. The management which the individual does in order to solve the problem, according to this theory (theory of cognitive discordance), includes the elimination or addition of new elements in order to restore balance (McLeod, 2018).

The theory of cognitive discordance as well as the Gestalt approach require the existence of an inner inclination of the individuals to maintain the harmony between the elements of attitudes and behaviors. However, Festinger's theory is restricted in describing this inclination which brings produces adaptive changes and does not refer to whether these ways the individual uses function. 
In order for the rehabilitation steps the individual takes to function, there should be certain requirements. The characteristics of a right decision conform with the individual's needs at a given moment as well as the rules of reason. The individuals are used to solving their problems in specific ways which they tend to repeat (Makroglou-Walls, Sfyridou \& Tsergas, 2001).

Gestalt describes this tendency from a different aspect, highlighting the fact that the individuals do the best they can in order to solve their problems, that is, in ways which make good use of the available resources and the resources of their environment (Yontef \& Jacobs, 2005). In addition, the problem-solving process can be carried out through a sudden comprehension which emerges from the characteristics of the things studied. In the Gestalt therapy, this moment may emerge through direct contact, focus or experimentation. In this way, problem solving is described as insight or insightfulness according to Kohler's aspect, who has been mentioned among the basic tenets of the approach. It is about a process in which the individual creates 'matchings' or connections and fills in the gaps in a spontaneous and creative way. The Gestalt approach to problem solving is different from the behavioral approaches of Pavlov and Thorndike which are regarded as progressive and learned processes (Makroglou-Walls et al., 2001).

\subsection{Holism and Personality Theory in Gestalt}

Holism refers to the unity of body and soul. The Gestalt approach rejects the dualisms of body and mind, thought and emotion, emotion and action and refers to the unification of these parts as well as the unification of the individual and the environment. The unification is the constitution of the individual who has the ability to self-regulate and adjust to constant change and requires the individual to experience the unity of body and mind (Australian Institute of Professional Counsellors, 2021). The humanitarian personality theories are holistic and this characterization renders them innate[ly] self-regulating for the individuals and oriented to their personal growth. Another characteristic of humanitarian theories is that the individuals and the symptoms they manifest cannot be understood out of their environment (Yontef \& Jacobs, 2005).

\subsection{Phenomenology}

An introduction to phenomenology, the roots of which date back to Goethe, is important in order to comprehend the Gestalt approach. It refers to the study of the structures of mindfulness as they are experienced from the first person's perspective. A core element of the experience is that it moves towards an object and this intention towards objects constitutes the experience along with facilitating factors which accompany it (Crowell, 2020). Phenomenology presumes that reality is shaped in relation to the observer and the observed, that is, it can be interpreted (Yontef \& Jacobs, 2005). The phenomenological method of mindfulness is followed in the Gestalt approach in order to enable, with the use of communication techniques, the individuals to experience it as wholeness. It separates the perception, the emotions and the action of the individual from the interpretations of the facts because it suggests that the interpretations lack the reliability of direct sense (Yontef, 1993). The descriptive study of mindfulness which takes place through dialogue and action results in the improvement of the individuals' consciousness when they interact (Yontef \& Jacobs, 2005). Among the phenomenological therapies are the Gestalt, the client-centered and the logical emotional behavioral.

\subsection{Existentialism}

Existentialism was a cultural movement in Europe during the 1940s and 1950s and was adopted by Sartre. Existentialism as the theory supports that freedom should be managed at the core of human existence as the foundation of other values. In general, existentialism suggests that we can neither comprehend human beings using terms from natural sciences, nor can it suffice for the scientific field to be enriched with moral theory categories (such as intention, character, and obligation). It is worth mentioning, as far as the approach is concerned, that existentialism can be 
defined as a philosophical theory which includes a total of categories which are governed by the norm of authenticity which is essential to human nature. Authenticity in existentialism, which may include moral assessments as well, constitutes the way in which individuals are involved in their work by being 'their real self, according to the German definition of the word 'authenticity', namely Eigentlichkeit. In addition, the concept of authenticity includes the characteristic of constant creation of the self, work in which the individuals may succeed by creating the self. In case this creation of the self is not completed, the individuals simply function according to the roles (Crowell, 2020).

\subsection{Paradox with the Theory of Change}

The paradox with the theory of change is the core of the Gestalt approach. What is described as a paradox is the fact that the more people try to be somebody else, the more they remain the same. The individuals' effort to be somebody else splits them rather than unifies them, where unity is their truth, that is their emotions, convictions, the position they stand for and their behaviors (the aforementioned authenticity) (Yontef \& Jacobs, 2005).

\section{Therapeutic Process}

The Gestalt therapy refers to the development and preservation of the state of functionality and well-being of the individuals and not to healing. The definition of health followed in this process coincides with the definition of health from the WHO (1946), according to which health is not merely the absence of illness but the state of a fully physical, mental and social well-being. Illness is perceived as a disruption in the natural inclination of the individual for self-regulation (Clarkson \& Cavicchia, 2013).

When studying health in the Gestalt approach, it appears first of all that the pursuit is a state of full functionality through 'full contact' or mindfulness. It separates full contact from simple information because mindfulness is a continuous state and constantly available to the individual (Witchel, 1973). This full contact means that individuals know what they are doing, how they are doing it and that they have alternatives: this comprehension makes the individual's choice more important. On the other hand, individuals cannot be in this healthy state when they verbally expresses their state but cannot see it, know it or react to it and do not feel responsive to it (Yontef, 1993).

The Gestalt therapists mention that the most pressing needs and incomplete behaviors are the ones which initiate efforts of completion or rehabilitation. They then become less conscious and others take their place. The satisfaction of needs is described as liberation since the individual will then proceed to shaping other unities. The emerging process of needs reminds the perceptual principle of the distinction of form-setting which was the root of the approach in the academic Gestalt psychology. It refers to the inclination to perceive complete forms and identify them through contrast based on a resulting clear meaning (Yontef \& Jacobs, 2005). During this process, the needs are perceived as being preventable, affect the individual's relationship with the environment and intervene in shaping new unities. The above potentials which relate to the selfregulation of the organism, according to the Gestalt perspective, exist within all individuals regardless of whether they are considered mature or immature in other standards (Witchel, 1973). Self-regulation has to do with the observation of what is happening and the sincerity of the self and others in relation to what they are willing to do and what they cannot do (Yontef \& Jacobs, 2005).

Freedom and development are pursued in this approach through the increase of mindfulness. Mindfulness, as what is happening here and now, is experienced in the Gestalt therapy integrating senses, emotions, thoughts, relationships and spirituality. By using the phenomenological method 
in the therapeutic dialogue, therapists focus on the direct perception of their clients, on the feelings and the differences of perspective, aiming at the individuals' realization of the present, of what they are doing and how they are doing it, and accepting it by giving credit to their self while observing the way they change from their actions (Yontef, 1993). More specifically, individuals achieve mindfulness in three ways, namely with contacting and responding to the environment through sensories, engaging actively in the present moment with no worries about the past or the future and taking responsibility for their choices instead of blaming others (Australian Institute of Professional Counselors, 2021).

Perls believed that therapy had an ultimate purpose for individuals: to accomplish a level of constitution which will facilitate their development. This means that the individuals will gradually pass from the support from the environment to the support of the self. These take place in the here and now because only in the present can there be self-regulation of the organism. During this process, the environment always needs to be seen as a whole with the individual, because that is where the elements that make the individual independent can be found. Therefore, sufficient support is the support from the self and the environment: we breathe because it is out there where we can find the air (Yontef \& Jacobs, 2005). In consulting, the practice that leans towards the Gestalt therapy is based on the unity of physical experience, the emotions, the language and the spirituality. The consultant describes his or her experience without attributing any causes to it, taking, in this way, an active part in what is happening. Personal growth is accomplished through the individual's struggle to maintain the balance between the satisfaction of needs and the restriction of tension (Clarkson \& Cavicchia, 2013). An important characteristic in the Gestalt approach for the individuals' personal growth is that the concept of full functionality includes the creative adjustment of the individuals who take the responsibility to balance the self with their environment (Yontef, 1993). Balance, as creative management, is found between the adjustment to the demands of the existing conditions and the point where individuals create something new which changes the environment. This process is two-directional; it is influenced by both the individual and the environment and no function of a living being is completed without an object from the outer environment, yet there is interaction everywhere (Witchel, 1973).

Bearing these facts in mind, the Gestalt therapy is more of an exploration than a direct modification of behavior and the therapist's role is to facilitate this process (Yontef, 1993). The relationship between the therapist and the client is what gives them both the potential to experience the present and to conduct this exploration (Australian Institute of Professional Counselors, 2021). The important therapeutic tools in this approach are awareness and dialogue (Yontef \& Jacobs, 2005). The presentation of the techniques of the approach presents difficulties because the approach does not have a history of technique material. As Witchel (1973) noted, Perls has not made any references to techniques in his books because it never crossed his mind to establish a 'school'. What follows are certain therapeutic techniques and processes with a focus on particular characteristics of a dialogue.

\subsection{Therapeutic Techniques and Processes}

The dialogue is a basic tool in the Gestalt approach. According to Yontef 's (1993) introduction in the Gestalt therapy, during the therapeutic relationship the emphasis is on four characteristics of the dialogue:

- The characteristic of integration, which refers to the safety provided by the direct experience of the other part as different, through experience sharing;

- The characteristic of active presence of the therapists, who express their thoughts, emotions and preferences directly without passing judgement or manipulating the client, using their presence to encourage the clients towards their autonomous regulation; 
- The commitment to the dialogue, where the therapist 'yields' to the contact that results from the interaction; and

- The experience of the dialogue which is action, including non-verbal elements.

A dialogue should include these characteristics in order to cultivate the kind of interpersonal contact which encourages the individual to experiment with solutions and encourage change in this way. The element of creativity during the process of the approach refers to the combination of different techniques which include verbal and non-verbal methods, such as awareness of sensories, breathing exercises, exercises using the body and the voice, expression of dreams and fantasies, drawing, and dancing. Non-verbal elements include body language (such as posture, voice, expressions, and hesitations) which are considered to reflect the condition the clients are experiencing at that moment. There are three tactics that follow with which the clients find it easier to focus on their bodies (Australian Institute of Professional Counselors, 2021):

- Identification, in which the therapist identifies the physical signs of the clients and refers to them in the dialogue and in action;

- Placing the sense physically, in which the clients are asked to show on their bodies where they experience the feeling to facilitate mindfulness; and

- Repetition, where the therapist asks from the clients to repeat one of their movements.

The techniques used are related to the processing of the question "What are you consciously experiencing at this moment?" and the guidance has to do with an experimentation - a game which is suggested to the clients in order for them to see more clearly what information they received after the counselor. Therefore, according to Yontef (1993), apart from the direct questions "How are you feeling now", the following techniques can be used:

- Reconstruction of feelings and thoughts which can be done by inviting the clients to say a few words in a kind of role play;

- Hyperbole, as a special form of reconstruction which makes the individuals feel a feeling, thought, or movement more intensely;

- Guided imagination, with which the individuals recreate a fact by focusing on visualization rather than reconstruction;

- Communication techniques which support the individuals to change their perspective by inviting them for instance, to imagine the opposite of what they believe to be true; and

- Techniques which promote awareness of physical functionality and how the individuals can use their bodies to have happy feelings, information and contact.

The techniques used in the approach have an active character and as they are applied to the clients, their repertoire expands with new tools. The techniques of the approach are taught to healers through oral processes which include training and monitoring. In essence, there are no techniques which can be introduced beforehand; but while the healer and the client exercise mindfulness, they are required to become more creative. The practice of the Gestalt approach is a way of existence and action rather than a total of techniques or a consulting prescription (Clarkson \& Cavicchia, 2013). What makes the approach special is that it is about an operation of a unified system which includes emotional, sensory, cognitive, interpersonal and behavioral elements (Yontef \& Jacobs, 2005). Emphasis is given to these different elements at various times, with the guiding principle of unification. The pursuit of the goal of the unification is based on the belief that the individuals wish to experience this totality (Clarkson \& Cavicchia, 2013).

Witchel (1973), in a full review of the literature concerning the Gestalt therapy, described a few more techniques which are widely used in the approach. He presented them under the term 'games': 
- Dialogue games among elements of the self, among parts of the body, where the clients try to guess the answer of the other part;

- Incomplete work, where the clients are required to fill in the dialogues that were never completed, the feelings that were never resolved;

- The projection game, where the clients are required to take an object and make some statements as if they were it;

- Withdrawal with their imagination, where the clients are required to go to a safe place mentally, when they wish to withdraw from the here and now. Then they are required to describe their experience during the withdrawal in the room;

- Physical movement, when incompatible elements are pointed out to the clients, for instance, verbal content and the tone of voice, and they are required to repeat these using hyperbole; and

- Reconstruction of a dream, with the therapeutic goal of covering the deficiencies of the client.

It is obvious that the interventions of the Gestalt therapeutic intervention, as experiments, combine the emphasis on the authentic relationship with the individual of the humane approaches with the dialogue of active methods. An example is the technique of the 'empty chair'. Working through this method targets the articulation of things that are difficult to be expressed to the people in the individual's real life and to the emergence of internal conflict. In this case, the individuals are required to imagine somebody, who is absent, sitting on the empty chair and to express to them freely what the individuals wish or are required to deal with a conflict with their inner criticism as if they were a figure sitting there. The counselors may suggest something during this experimentation or they may just refer to something they notice at that very moment so that the expressed emotional state can be clarified (Yontef \& Schulz, 2016).

In addition, Witchel (1973) cited the following techniques-rules:

- The rule of 'now as a functional concept which refers to what the individual is doing. Conversations about the past are encouraged in present time;

- A simple, authentic interaction between at least two individuals;

- Phrases in the first person, which facilitate both interpersonal contact and focus on oneself, and generally a vocabulary which promotes assumption of responsibility,

- The use of constant mindfulness, where certain knowledge of oneself results from the senses of the body; and

- The rule of not speaking about somebody who is not present but addressing him or her directly (for example, to an empty chair).

\subsection{Applications of the Approach}

The Gestalt therapy has been applied to every context. Owing to the fact that it focuses on the process, it can function effectively with every category of clients, mainly based on the relationship that develops between the healer and the healed. The requirement is that the healers should feel at ease in their relationship with their clients so that they can adjust the general principles of the approach to the clients' needs (Yontef \& Jacobs, 2005).

The Gestalt approach is known to be applied to groups; however, it remains an individual approach (Yontef, 1993). More often, group therapy becomes part of a Gestalt therapeutic program. Generally, there are three models to which the principles apply, namely techniques, movement and focussing on one another (Yontef \& Jacobs, 2005):

- The participants work one on one with the healer and the others observe. Afterwards, there is feedback from the participants; 
- The participants interact with each other, with emphasis on communication 'here and now'; and

- A mixed model in which both of the above are applied in the same group.

There are short-term and long-term therapies. The applications of the approach vary from individual sessions as intervention during crises and applications to groups, organizations, and schools, to applications which have functioned with individuals with psychosis, psychosomatic disorders and post-traumatic stress (Yontef \& Jacobs, 2005). The healers of the Gestalt approach work with all ages; there is also individual therapy for children which constitutes part of family therapy. Resources concerning the approach recognize its contribution to the fields of education, the improvement of the community, art, religion, mental health and groups of adolescents, children, services of supervisors of minors, families, couples, and students. There are various studies which corroborate its efficiency on personal growth as well (Witchel, 1973). Generally, however, it is not so simple to approach matters of corroboration using data concerning the effectiveness of this kind of treatment. According to the spirit of the approach, every pair of healer and client is unique; it bears complex meanings which could not potentially be measured and this further adds to the uniqueness of every healer and functions within the framework that suits them. Although there have been efforts in order to develop methods which will show sensitivity for personal meanings, for various reasons corroboration remains a challenge; even within the community of the Gestalt approach the matter of research remains ambiguous (Yontef \& Jacobs, 2005).

Given the fact that there are no standards in the use of the techniques of the approach, the introduction to its applications will be concluded with the requirements concerning the background of the healer. The application of the techniques requires a course of personal growth and wisdom of the healer. Thus, in addition to the training in the beginning, and the practical application of the Gestalt approach, healers require a background in personality theory, psychopathology and diagnosis, theories and applications of other psychotherapy systems, knowledge of psychodynamics and personal therapy, as well as higher level of clinical training, monitoring and experience. This background is important because in the approach, creativity is encouraged both in and out of sessions (Yontef \& Jacobs, 2005).

\subsection{Overview and Critical Perspective of the Approach}

The main idea of the Gestalt approach is wholeness. This wholeness is composed ofspecial parts without which a living organism cannot exist. The Gestalt concept as a uniform entity permeates the therapeutic goals which aim at the mindfulness of the interdependent relationship of the parts of the whole and ultimately contributes to the satisfaction of the individual's needs and personal growth as well as the course towards self-regulation or freedom. At the same time, the idea of wholeness is the essence of the approach: the concept of the compositional form of the approach itself is a Gestalt, that is an (autonomous) entity which is composed in harmony by various cultural and spiritual trends and appears as an alternative to the main trends of behaviorism and classical psychoanalysis (Yontef \& Jacobs, 2005).

The approach is presented as a third authentic course of experimentation which is not like the learning in behaviorism and the effort of understanding in psychoanalysis. The principles of the approach as a third path are compatible with those in other humanitarian approaches (Clarkson \& Cavicchia, 2013). The Gestalt approach encourages individuals to conform with themselves by getting to know themselves, instead of trying to conform with norms. Because the element of creative adjustment characterizes it, this differentiates it from the individual's adjustment which is the goal of psychoanalysis, also seen as conformist and stereotypical (Yontef, 1993). In the 
background of the approach, emphasis was given to the fact that Goldstein influenced Perls as his mentor, who suggested that such creativity is the ability of individuals to come up with new norms.

At this point, it is worth mentioning the concept of experimentation. The attempt from the clients to try something new and put it into practice, which in this approach does not become mandatory to be adopted as behavior from the clients, increases their understanding and their awareness of things that they had missed out. This process, on one hand, constitutes an alternative to the verbal methods which have been used by the other two trends of psychoanalysis and behaviorism, and on the other, it is suggested as a creative component of the therapy which facilitates personal growth (Yontef \& Jacobs, 2005). The Gestalt approach is based on the notion that individuals have their own intelligence or logic to make decisions at every given moment. This is an important characteristic of human approaches because positive expectations influence performances in a positive way. There are research data available that show that students perform according to their teachers' expectations: when a teacher believes that students are unable to learn, the students' performance is lower, regardless of their own abilities (Clarkson \& Cavicchia, 2013).

In terms of this point of view, Gestalt is similar to the client-centered approach which means that healers are supportive, show empathy, are kind and focused on their clients' experience, without possessing objective knowledge (Yontef \& Jacobs, 2005). However, a significant difference of the Gestalt concerns the role of the healer: the healer provides interpretations and pursues the experience and insight of the client. This is contrary to the Rogerian therapy whereby the healer remains passive and is limited to the use of reflection and clarifications (Yontef, 1993). This means that the healer is engaged in an active and personal way, encouraging the other individual to function as truthfully and authentically as the healer does. The Gestalt approach integrates the concepts of authenticity and responsibility, as the healer and the client are encouraged to speak their minds, experiencing one another's real self, so that in this way they share mindfulness (Yontef, 1993). It is safe to say that the healer does not have a particular role other than the role of the facilitator. There are active techniques in order to clarify, through the dialogue, the irrational beliefs and behavioral changes a healer expects. These techniques support realization because they bring out emotions that had been underrated and suppressed and complete dialogues and situations uncompleted. An important contribution of the approach is that during this process non-verbal expressions are also included (Yontef, 1993).

\section{Conclusions}

The Gestalt approach is based on the conviction that individuals possess all the necessary elements for their personal growth and that this growth can be accomplished within relationships that give them the potential to function authentically. Among the strengths of the approach is the fact that there is empirical research which supports the therapeutic Gestalt approach and its techniques in which advantages have been corroborated during its application for certain disorders. Another important fact is that it can work with the past and relate it to the present. Additionally, it is flexible, using various options of techniques which can be adjusted to various therapeutic results (Australian Institute of Professional Counselors, 2021). Another positive element of the approach is that it can be applied to individuals regardless of age, level, or cultural background and to various situations. Through the approach individuals are empowered with the right to be different and unique while using this therapeutic approach. They are also given the ability not to release their discomfort but to develop their hidden dynamics and ability to come up with new norms. However, certain weaknesses of the approach should be taken into account. For example, the Gestalt healer is required to possess a high level of personal growth. In addition, there is no limited possibility to corroborate the effectiveness of the therapeutic techniques. Finally, the approach does not possess a strong theoretical base (Australian Institute of Professional Counselors, 2021). 
It is worth mentioning that the Gestalt therapy cannot be learned through words, by reading or writing; it is contrary to what the approach stands for, and to quote Witchel (1973, p.7): "Real learning can only come from the direct contact with the Gestalt healer or a person who has been engaged in the Gestalt way of life... the gestalt therapy is my experience and your experience ..." (Witchel, 1973, p.7).

\section{References}

Australian Institute of Professional Counsellors. (2021). https://www.aipc.net.au/articles/

Britannica, T. Editors of Encyclopaedia (2020). Gestalt psychology. Encyclopedia Britannica. https://www.britannica.com/science/Gestalt-psychology

Clarkson, P., \& Cavicchia, S. (2013). Gestalt counselling in action. Sage. https://uk.sagepub.com/sites/default/files/upm-binaries/57778_Clarkson_with_Cavicchia.pdf

Crowell, S. (2020). Existentialism,. The Stanford Encyclopedia of Philosophy. Edward N. Zalta (ed.). https://plato.stanford.edu/archives/sum2020/entries/existentialism/

Festinger, L. (1957). A theory of cognitive dissonance. Stanford University Press.

Perls, F. S., \& Andreas, S. (1969). Gestalt therapy verbatim. Lafayette, Calif.: Real People Press.

Makroglou-Walls, M., Sfyridou, P., \& Tsergas, N. (2001). Elements of general and evolutionary psychology. Greek Ministry of Education and Religious Affairs, Institute of Education. http://ebooks.edu.gr/ebooks/handle/8547/3827

McLeod, S. (2018). Cognitive dissonance. https://www.simplypsychology.org/cognitive-dissonance.html

Samartzi, S. (1995). Introduction to cognitive functions. Papazissi Publications.

The Gestalt Centre. (2021). The birth of gestalt. https://gestaltcentre.org.uk/what-is-gestalt/

Yontef, G. M. (1993). Awareness, dialogue and process: Essays on gestalt therapy. The Gestalt Journal Press.

Yontef, G., \& Jacobs, L. (2005). Gestalt therapy. In R. J. Corsini \& D. Wedding (Eds.), Current psychotherapies (pp. 299-336). Thomson Brooks/Cole Publishing Co.

Yontef, G., \& Schulz F. (2016). Dialogue and experiment. British Gestalt Journal, 25(1), 9-21.

WHO (1946). Constitution of the world health organization. New York, 19-22 June, 1946. https://treaties.un.org/doc/Treaties/1948/04/19480407\%2010-51\%20PM/Ch_IX_01p.pdf

Witchel, R. (1973). Gestalt therapy: Development, theory and techniques [Paper presentation]. The American Personnel and Guidance Association Meeting. Atlanta, Georgia. https:// files.eric.ed.gov/fulltext/ED082090.pdf 